\title{
Intensity of hospital resource use following traumatic brain injury: a multicentre cohort study, 2013-2016
}

\author{
Coralie Assy, MSc \\ Lynne Moore, PhD \\ Teegwendé Valérie Porgo, PhD \\ Imen Farhat, MSc \\ Pier-Alexandre Tardif, MA, MSc \\ Catherine Truchon, PhD \\ Henry T. Stelfox, MD, PhD \\ Belinda J. Gabbe, PhD \\ François Lauzier, MD, MSc \\ Alexis F. Turgeon, MD, MSc \\ Julien Clément, MD
}

Presented at the Trauma Association of Canada Annual Scientific Meeting 2018 Feb. 22, 2018, Toronto, Ont.

\section{Accepted Mar. 31, 2021}

\section{Correspondence to: \\ C. Assy \\ Population Health and Optimal Health Practices Research Unit Centre hospitalier universitaire de Québec - Université Laval $1401,18^{\mathrm{ème}}$ rue, local Z-201 Québec QC G1J 1 Z4 \\ coralie.assy.1@ulaval.ca}

Cite as: Can J Surg 2022 March 2; 65(2). doi: $10.1503 /$ cjs.007819

\begin{abstract}
Background: The knowledge gap regarding acute care resource use for patients with traumatic brain injury (TBI) impedes efforts to improve the efficiency and quality of the care of these patients. Our objective was to evaluate interhospital variation in resource use for patients with TBI, identify determinants of high resource use and assess the association between hospital resource use and clinical outcomes.
\end{abstract}

Methods: We conducted a multicentre retrospective cohort study including patients aged 16 years and older admitted to the inclusive trauma system of Quebec following TBI, between 2013 and 2016. We estimated resource use using activity-based costs. Clinical outcomes included mortality, complications and unplanned hospital readmission. Interhospital variation was evaluated using intraclass correlation coefficients (ICCs) with 95\% confidence intervals (CIs). Correlations between hospital resource use and clinical outcomes were evaluated using correlation coefficients on weighted, risk-adjusted estimates with $95 \%$ CIs.

Results: We included 6319 patients. We observed significant interhospital variation in resource use for patients discharged alive, which was not explained by patient case mix (ICC $0.052,95 \%$ CI 0.043 to 0.061 ). Adjusted mean resource use for patients discharged to long-term care was more than twice that of patients discharged home. Hospitals with higher resource use tended to have a lower incidence of mortality $(r-0.347,95 \%$ CI -0.559 to -0.087$)$ and unplanned readmission $(r-0.249,95 \% \mathrm{CI}-0.481$ to 0.020$)$ but a higher incidence of complications $(r 0.491,95 \%$ CI 0.255 to 0.666$)$.

Conclusion: Resource use for TBI varies significantly among hospitals and may be associated with differences in mortality and morbidity. Negative associations with mortality and positive associations with complications should be interpreted with caution but suggest there may be a trade-off between adverse events and survival that should be evaluated further.

Contexte : Le manque de données sur l'utilisation des ressources en soins aigus chez les patients victimes d'un traumatisme crânien (TC) nuit aux efforts pour améliorer l'efficience et la qualité de leurs soins. Notre objectif était d'évaluer les variations quant à l'utilisation des ressources chez les patients victimes de traumatismes crâniens entre les hôpitaux, d'identifier les déterminants d'une grande utilisation des ressources et d'analyser le lien entre l'utilisation des ressources hospitalières et les résultats cliniques.

Méthodes : Nous avons procédé à une étude de cohorte rétrospective multicentrique sur des patients âgés de 16 ans et plus admis dans le système intégré de traumatologie au Québec après un TC, entre 2013 et 2016. Nous avons estimé l'utilisation des ressources à partir des coûts basés sur les activités. Les résultats cliniques incluaient mortalité, complications et réhospitalisation non planifiée. La variation entre les hôpitaux a été évaluée à l'aide de coefficients de corrélation intraclasse (CCIC), avec des intervalles de confiance (IC) de $95 \%$. Les corrélations entre l'utilisation des ressources hospitalières et les résultats cliniques ont été évaluées à l'aide de coefficients de corrélation sur les estimations pondérées, ajustées en fonction du risque, avec des IC de $95 \%$.

Résultats : Nous avons inclus 6319 patients. Nous avons observé des variations significatives entre les hôpitaux pour ce qui est de l'utilisation des ressources chez les patients ayant reçu leur congé de l'hôpital et elle n'a pas pu être expliquée par la clientèle (CCIC 0,052, IC de $95 \%$ 0,043 à 0,061). L'utilisation moyenne ajustée des ressources chez les patients transférés vers un établissement de soins prolongés était 
au-delà de 2 fois plus élevée que chez les patients ayant reçu leur congé de l'hôpital. Les hôpitaux qui ont utilisé davantage de ressources ont eu tendance à avoir une incidence moindre de mortalité $(r-0,347$, IC de $95 \%-0,559$ à -0,087) et de réadmissions non planifiées $(r-0,249$, IC de $95 \%-0,481$ à 0,020$)$, mais une incidence plus élevée de complications ( $r 0,491$, IC de $95 \% 0,255$ à 0,666$)$.

Conclusion : L'utilisation des ressources pour les TC varie significativement d'un hôpital à l'autre et pourrait être associée à des différences de mortalité et de morbidité. Les associations négatives avec la mortalité et positives avec les complications devraient être interprétées avec prudence, mais suggèrent qu'il y aurait lieu d'analyser plus en profondeur le rapport entre événements défavorables et survie.

I $\mathrm{n}$ North America, traumatic brain injury (TBI) is an important cause of mortality and disability for youth and older adults. ${ }^{1,2}$ TBI is responsible for nearly half of all injury-related deaths in the world and $30 \%$ in the United States. ${ }^{1,3}$ Direct and indirect costs of TBI were estimated at $\$ 76.5$ billion in the US for $2010 .^{4}$

Previous research has shown interhospital variation in risk-adjusted mortality for TBI admissions in Canada. ${ }^{5}$ Moreover, while regional variations in costs have been observed for trauma care, higher spending was not associated with better patient outcomes in US trauma centres. ${ }^{6}$ These results suggest that resource use is driven by factors other than patient case mix. Research in chronic disease populations suggests that other factors influencing resource use include delays to care and to discharge, and care intensity, both driven by the availability of human and material resources. ${ }^{7-9}$

Despite the large financial burden of TBI, we have a limited understanding of resource use in this population, particularly in universal health systems. The lack of patient-level data on resource use for patients with TBI has hampered attempts to improve the efficiency and the quality of care for these patients. The objectives of this study were to evaluate interhospital variation in riskadjusted hospital resource use, identify determinants of high hospital resource use intensity and evaluate the association between hospital resource use and clinical outcomes for TBI.

\section{Methods}

\section{Study design, setting and study data}

We conducted a multicentre, retrospective cohort study of patients with TBI admitted to any designated adult trauma centre in the inclusive trauma system of the province of Quebec, Canada, between Apr. 1, 2013, and Mar. 31, 2016. The Quebec trauma system includes 57 adult trauma centres: 3 level I centres, 5 level II centres, 21 level III centres and 28 level IV centres. All trauma centres undergo mandatory accreditation by the provincial accreditation agency, and designation levels are based on the American College of Surgeons' trauma centre verification criteria. Only level I and II centres have neurosurgical capacity so patients with moderate and severe TBI should be directly transported or transferred to these centres. We used linked data from the Quebec trauma registry and the Quebec hospital discharge database. Data for unit costs were extracted from hospital financial reports (AS-471) for 2015-2016. ${ }^{10,11}$

\section{Population}

We included all patients 16 years of age and older who were admitted to any adult trauma centre following TBI in the province of Quebec, Canada, who met at least 1 of the following criteria: in-hospital death, hospital admission of 3 days or longer, intensive care unit (ICU) admission or transfer from another acute care hospital. We defined TBI using the following Abbreviated Injury Scale (AIS 2008) codes: 113000.6, 116002.3, 116004.5, 120202.5 to $122899.3,130202.2$ to $132699.2,140202.5$ to 140799.3, and 150200.3 to $150408.4 .{ }^{12}$ We excluded patients who left the hospital against medical advice and patients who were dead on arrival in the emergency department or arrived without vital signs and died within 30 minutes of arrival in the emergency department.

\section{Outcomes}

Our primary outcome was hospital resource use, estimated using activity-based costing, in line with the Grading of Recommendations Assessment, Development and Evaluation (GRADE) recommendations ${ }^{13}$ and according to Canadian guidelines for the economic evaluation of health technologies. ${ }^{14}$ Detailed information on this costing method for injury admissions in Quebec has been published elsewhere. ${ }^{15}$ In brief, units of hospital resource use, extracted from the trauma registry, were multiplied by unit costs, extracted from hospital financial reports, for each of 6 activity centres: emergency department, general ward, operating room, ICU, medical imaging and para-clinical services (physiotherapy, respiratory therapy, psychotherapy and occupational therapy). For example, hospital resource use for a patient who went through the emergency department (\$253.37/visit), 
stayed 4 hours in the operating room $(\$ 1129.11 / \mathrm{h})$, stayed 3 days in the ICU $(\$ 1212.07 / \mathrm{d})$, stayed 10 days on a medical ward $(\$ 342.58 / \mathrm{d})$, underwent magnetic resonance imaging (\$216.70/unit) and had 5 hours of occupational therapy $(\$ 76.14 / \mathrm{h})$ is estimated at $\$ 12429.22$. We were able to obtain only a fixed cost estimate for emergency department resource use, so while emergency department costs were included in cost estimates, we did not perform analyses specifically for this activity centre. To obtain unit costs that were not influenced by geographic or temporal pricing fluctuations, we used average unit costs of each activity centre from the 3 level I trauma centres (2016 Canadian dollars). Hospital resource use did not include physician billing data.

Secondary outcomes were mortality, complications and unplanned readmission. Deaths occurring between arrival at the emergency department and discharge were included in analyses on mortality. For complications, we considered the occurrence of at least 1 complication during the patient's stay as an event. Complications were based on a previously validated list of conditions potentially related to care (Appendix 1, Table e1, available at www.canjsurg.ca/lookup/doi/10.1503/cjs.007819/tab -related-content). ${ }^{16}$ Only hospital admissions were included and in-hospital death was considered as a complication. Readmission was evaluated among patients discharged alive and was defined as an unplanned admission to any acute care hospital in the province within 30 days of discharge, regardless of the reason. This definition excluded the following: transfers to another hospital on the same day as discharge, admissions for follow-up visits or elective surgeries, rehabilitation or transition care, and admission to long-term care facilities. ${ }^{17}$

\section{Statistical analysis}

To assess interhospital variation in hospital resource use, we compared resource use across trauma centres while adjusting for differences in patient case mix. Adjustment is necessary because patients treated at 1 centre may be sicker (more severely injured, older, more comorbidities) than those treated at another centre. To do so, we used a multilevel linear model with hospital modelled as a random intercept and the following variables describing patient case mix modelled as fixed effects: age (16-54 yr, 55-64 yr, 65-74 yr, 75-84 yr, $\geq 85 \mathrm{yr}$ ), sex, number of comorbidities $(0,1,2,3, \geq 4)$, maximum AIS (MAIS) score of TBI $(2,3$, 4, 5-6), MAIS score of concomitant injuries $(0,1,2,3,4$, 5-6), transfer in from another hospital (yes, no), systolic blood pressure (SBP) $(<90 \mathrm{~mm} \mathrm{Hg}, \geq 90 \mathrm{~mm} \mathrm{Hg})$, Glasgow Coma Scale (GCS) score (continuous) and respiratory rate (< 10 or $\geq 30$ breaths/min, 10-29 breaths/min). GCS score, SBP and respiratory rate were all measured on arrival at the emergency department. The GCS score was evaluated by the treating physician.
To quantify interhospital variation, we calculated intraclass correlation coefficients (ICCs) and 95\% confidence intervals (CIs). ICCs indicate the percentage of variation in the outcome (resource utilization) between clusters (hospitals) that is not explained by covariables ${ }^{18}$ and have been used to asses interhospital variation in other populations. ${ }^{19}$ ICCs less than $5 \%, 5 \%-20 \%$ and greater than $20 \%$ are considered to represent low, moderate and high interprovider variation, respectively. ${ }^{20} \mathrm{We}$ calculated the CIs of ICCs using bootstrap resampling. ${ }^{21,22}$

We used shrinkage estimates to estimate mean hospital resource use for each trauma centre. ${ }^{23,24}$ In brief, this method shrinks observed estimates to the global mean by a factor that is the inverse of their variance. Owing to the right-skewed distribution of activity-based costs, we logtransformed them for analyses. We performed subgroup analyses for activity centres (general ward, operating room, ICU, medical imaging and paraclinical services), for age groups ( $<65$ and $\geq 65 \mathrm{yr}$ ) and for type of TBI (isolated TBI [no concomitant injury with AIS score $\geq 2$ ] and severe TBI [MAIS score $\geq 4]$ ).

To identify patient-level determinants of hospital resource use intensity, we calculated geometric mean ratios $^{25}$ with $95 \%$ CIs using a multilevel linear model including the following potential determinants identified by literature review and clinical experts: age, sex, number of comorbidities, MAIS score of TBI, MAIS score of concomitant injuries, SBP, GCS score, respiratory rate, transfer in from another hospital, payer agency and discharge destination. We used a random intercept to account for clustering of observations by hospital.

To calculate risk-adjusted incidence of in-hospital mortality, in-hospital complications and unplanned 30-day hospital readmission, we used risk adjustment based on models derived and validated previously. ${ }^{26}$ In brief, we used a multilevel logistic model including age, sex, number of comorbidities, MAIS score of TBI, MAIS score of concomitant injuries, SBP, GCS score, respiratory rate and transfer in from another hospital.

To evaluate the association between hospital resource use intensity (estimated as risk-adjusted mean activitybased costs) and clinical outcomes (risk-adjusted incidence of mortality, complications and unplanned readmissions), we calculated Pearson correlation coefficients $(r)$ on Fisher Z-transformed proportions, weighted by average annual hospital volume of patients with TBI. We performed subgroup analysis by age groups. We then restricted the analysis to isolated TBI, severe TBI and level I and II trauma centres.

We simulated missing data using multiple imputation with the Markov chain Monte Carlo method. ${ }^{27,28} \mathrm{We}$ imputed each missing value 12 times on the basis of the highest proportion of missing data using models containing all independent and dependent variables included in analytic models. 
In our sensitivity analyses, we first performed analyses excluding patients with missing data and patients older than 85 years of age. This age cut-off was based on the literature on level of care decisions. ${ }^{29}$ Second, as resource use is largely driven by either the duration of care (influenced by delays in care or delays to discharge) or intensity of care (influenced by level of care decisions), ${ }^{7-9}$ the project steering committee grouped activity centres according to these concepts for subgroup analyses. Thus, resource use related to the general ward was chosen to represent duration of care, and resource use related to the ICU, operating room, medical imaging and paraclinical services was chosen to represent intensity of care. Third, we included deaths using Fine-Grey competing risks models. ${ }^{30}$

All analyses were performed using Statistical Analysis System (SAS) software (version 9.4, SAS Institute Inc.). Statistical tests were 2-sided with statistical significance set at $5 \%$. This study was approved by the Centre hospitalier universitaire de Québec - Université Laval research ethics committee.

\section{Results}

\section{Study population}

During the study period, 6645 patients with TBI aged 16 years of age and older were admitted to the 57 adult trauma centres in Quebec. We excluded patients who were dead on arrival $(n=168 ; 2.5 \%)$, arrived without vital signs and died within 30 minutes of arrival $(n=121 ; 1.8 \%)$ and left the emergency department against medical advice $(n=37 ; 0.6 \%)$.

The study sample comprised 6319 patients. Of these, 5267 were discharged alive from 55 trauma centres (2 level IV trauma centres had no TBI admissions over the study period). A total of $56.6 \%$ were 65 years of age or over, $47.0 \%$ had a severe TBI (AIS score $\geq 4$ ) and $27.8 \%$ had a GCS score of less than 13 on arrival (Appendix 1, Table e2). Level I and II centres (neurotrauma centres) treated $55.3 \%$ and $20.5 \%$ of TBI admissions, $66.3 \%$ and $22.8 \%$ of patients with severe TBI (AIS score $\geq 4$ ), $68.3 \%$ and $21.5 \%$ of patients with a GCS score of $9-12$ and $80.0 \%$ and $17.3 \%$ of patients with a GCS score of less than 9 on arrival. In this study, $0.69 \%, 6.41 \%$ and $9.26 \%$ of patients had missing data for SBP, respiratory rate and GCS score, respectively.

Median patient activity-based costs were $\$ 5939$ (interquartile range [IQR] \$3250-\$11 687; Appendix 1, Table e2) for patients discharged alive. Mean patient activity-based costs were $\$ 10108$ (standard deviation [SD] $\$ 11$ 975). Median and mean lengths of stay for these patients were 11 days (IQR 6-21 d) and 17.0 days [SD $19.1 \mathrm{~d}$ ], respectively. The majority of patients were older than 65 years of age $(56.6 \%)$ and male $(64.9 \%)$. The most frequent mechanism of injury was falls (63.7\%).

\begin{tabular}{|c|c|}
\hline Variable & ICC $(95 \% \mathrm{Cl})$ \\
\hline All resource use & 0.052 (0.043 to 0.061$)$ \\
\hline \multicolumn{2}{|l|}{ Activity centre } \\
\hline General ward & 0.052 (0.038 to 0.067 ) \\
\hline ICU & 0.089 (0.078 to 0.100$)$ \\
\hline Operating room & 0.204 (0.181 to 0.226$)$ \\
\hline Medical imaging & 0.081 (0.077 to 0.085$)$ \\
\hline Paraclinical services & 0.151 (0.133 to 0.169 ) \\
\hline \multicolumn{2}{|l|}{ Patient age, yr } \\
\hline$<65$ & 0.080 (0.071 to 0.089 ) \\
\hline$\geq 65$ & 0.060 (0.050 to 0.070$)$ \\
\hline \multicolumn{2}{|l|}{ Type of traumatic brain injury } \\
\hline Isolated & 0.058 (0.035 to 0.082$)$ \\
\hline Severe (MAIS score $\geq 4$ ) & 0.103 (0.095 to 0.112$)$ \\
\hline \multicolumn{2}{|l|}{ Trauma centre level } \\
\hline I and II & 0.040 (0.007 to 0.073$)$ \\
\hline III and IV & 0.039 (0.005 to 0.073$)$ \\
\hline
\end{tabular}

\section{Interhospital variation in hospital resource use}

Moderate interhospital variation in hospital resource use was observed across the 55 trauma centres after adjustment for patient case mix (ICC 0.052 , 95\% CI 0.043 to 0.061; Table 1 and Figure 1). Interhospital variation was highest for the operating room (ICC $0.204,95 \%$ CI 0.181 to 0.226 ) and lowest for the ward (ICC $0.052,95 \%$ CI 0.038 to 0.067; Table 1). Overall, 8 trauma centres had a significantly higher hospital resource use than the provincial mean, including the 3 level I centres. Only 2 (level II) trauma centres had a lower hospital resource use than the provincial mean (Figure 1). We noted a higher interhospital variation in hospital resource use for severe TBI (MAIS score $\geq 4$; ICC 0.103, 95\% CI 0.095 to 0.112 ) and for patients younger than 65 years of age (ICC $0.080,95 \%$ CI 0.071 to 0.089 ; Table 1 ).

\section{Patient-level determinants of hospital resource use intensity}

Hospital resource use intensity increased with the number of comorbidities, the MAIS score of the TBI and the MAIS score of concomitant injuries (all $p<0.0001$; Table 2). Adjusted hospital mean resource use was $41 \%$ higher for patients in shock on arrival (SBP < 90) and 30\% higher for patients with a respiratory rate less than 10 breaths/min or greater than or equal to 30 breaths/min than for their counterparts. Hospital resource use intensity for patients with a GCS score of 8 or below was twice that for patients with a GCS score of 13 or above $(p<$ $0.001)$ and it was higher for patients discharged to longterm care or rehabilitation. 


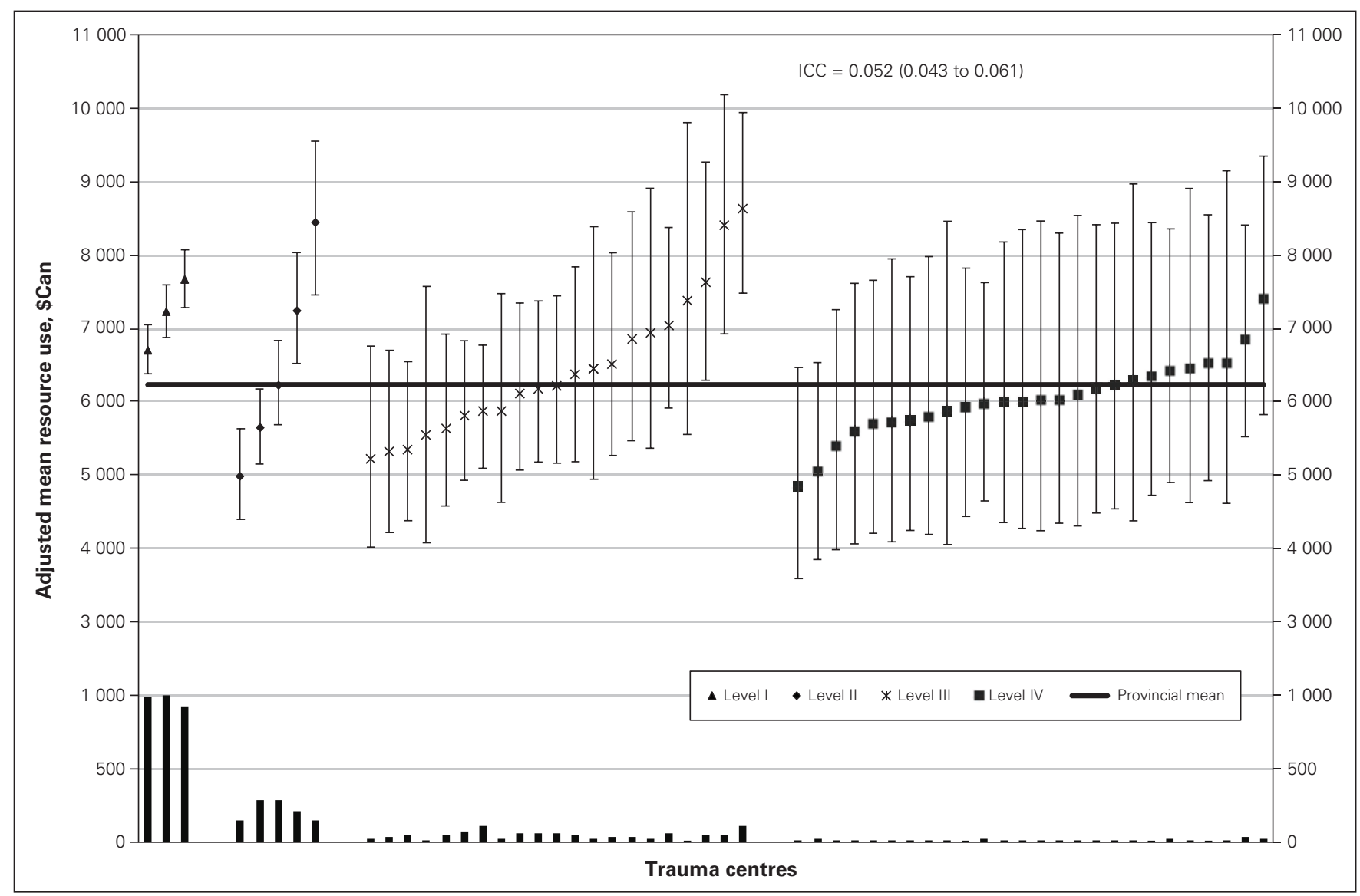

Fig. 1. Interhospital variation in hospital resource use following traumatic brain injury. ICC = intraclass correlation coefficient. Values in parentheses are $95 \%$ confidence intervals.

\section{Association between interhospital resource use and clinical outcomes}

Seventeen percent of the study population $(1052 / 6319)$ died in hospital, $35.9 \%$ of patients $(2270 / 6319)$ had at least 1 in-hospital complication and $9.9 \%$ of patients discharged alive (521/5267) had an unplanned readmission within 30 days of discharge. Trauma centres with higher risk-adjusted hospital resource use had a significantly lower risk-adjusted incidence of mortality $(r-0.347,95 \%$ CI -0.559 to -0.087 ; Figure 2A). They tended to have a lower incidence of readmission $(r-0.249,95 \%$ CI -0.481 to 0.020 ; Figure 2B), but this association was not statistically significant. The risk-adjusted incidence of complications was higher for trauma centres with higher riskadjusted hospital resource use $(r 0.491,95 \%$ CI 0.255 to 0.666; Figure 2C). In subgroup analyses, the association between hospital resource use and mortality was stronger for younger patients $(<65 \mathrm{yr})$ and for level I and II centres (Table 3). Associations between hospital resource use and complications were stronger for younger patients and for level I and II centres. However, correlation coefficients did not reach statistical significance because of low sample sizes. For readmission, a stronger association was observed for patients with isolated TBI (Table 3).

\section{Sensitivity analyses}

Interhospital variation in risk-adjusted hospital resource use was slightly higher when we excluded patients aged 85 years of age and older (ICC 0.062 v. 0.052 for the main analysis). Variation was lower when we excluded patients with missing data (ICC 0.035 ), probably because there was less heterogeneity among patients with complete data; GCS scores are more frequently missing in patients with mild TBI or those intubated and sedated on arrival. In analyses evaluating the correlation between mean risk-adjusted hospital resource use and clinical outcomes, stronger correlations for mortality and complications were observed when patients aged 85 years and older or patients with missing data were excluded (Appendix 1, Table e3). The association between riskadjusted mean hospital resource use and risk-adjusted incidence of unplanned readmission was statically significant when patients aged 85 years and older were excluded $(r-0.339,95 \%$ CI -0.554 to -0.075$)$. When activity centres were divided according to whether they were likely 
Table 2 (part 1 of 2). Determinants of hospital resource use intensity

\begin{tabular}{|c|c|c|c|}
\hline Variable & $n(\%)$ & $\begin{array}{l}\text { Geometric mean ratio of costs } \\
\qquad(95 \% \mathrm{Cl})\end{array}$ & $p$ value \\
\hline Overall & $5267(100)$ & & \\
\hline \multicolumn{4}{|l|}{ Age, yr } \\
\hline $16-54$ & 1519 (28.8) & Ref. & 0.04 \\
\hline $55-64$ & 768 (14.8) & $1.02(0.95$ to 1.10$)$ & 0.04 \\
\hline $65-74$ & $949(18.0)$ & 1.09 (1.02 to 1.17$)$ & 0.04 \\
\hline $75-84$ & $1157(22.0)$ & 1.09 (1.01 to 1.18$)$ & 0.04 \\
\hline$\geq 85$ & $874(16.6)$ & $1.10(1.01$ to 1.19$)$ & 0.04 \\
\hline \multicolumn{4}{|l|}{ Sex } \\
\hline Female & $1851(35.1)$ & Ref. & 0.07 \\
\hline Male & 3456 (64.9) & 1.05 (1.00 to 1.10$)$ & 0.07 \\
\hline \multicolumn{4}{|l|}{ Number of comorbidities } \\
\hline 0 & $2893(54.9)$ & Ref. & $<0.001$ \\
\hline 1 & $1278(24.3)$ & 1.09 (1.04 to 1.15$)$ & $<0.001$ \\
\hline 2 & 647 (12.3) & 1.25 (1.16 to 1.34$)$ & $<0.001$ \\
\hline 3 & $277(5.3)$ & $1.23(1.11$ to 1.36$)$ & $<0.001$ \\
\hline$\geq 4$ & $172(3.3)$ & 1.35 (1.19 to 1.54$)$ & $<0.001$ \\
\hline \multicolumn{4}{|l|}{ MAIS of traumatic brain injury } \\
\hline 2 & $736(14.0)$ & Ref. & $<0.001$ \\
\hline 3 & $2053(39.0)$ & 1.02 (0.96 to 1.09 ) & $<0.001$ \\
\hline 4 & $943(17.9)$ & 1.15 (1.07 to 1.24$)$ & $<0.001$ \\
\hline 5 and 6 & $1535(29.1)$ & $1.38(1.28$ to 1.48$)$ & $<0.001$ \\
\hline \multicolumn{4}{|l|}{ MAIS of concomitant injuries } \\
\hline None & $1487(28.2)$ & Ref. & $<0.001$ \\
\hline 1 & $1284(24.4)$ & $0.98(0.92$ to 1.04$)$ & $<0.001$ \\
\hline 2 & 1279 (24.3) & 1.15 (1.08 to 1.22$)$ & $<0.001$ \\
\hline 3 & $914(17.4)$ & $1.68(1.56$ to 1.80$)$ & $<0.001$ \\
\hline 4 & $195(3.7)$ & 2.19 (1.93 to 2.48$)$ & $<0.001$ \\
\hline 5 and 6 & $108(2.1)$ & 2.62 (2.23 to 3.09 ) & $<0.001$ \\
\hline \multicolumn{4}{|l|}{ Systolic blood pressure $\left(\mathrm{mm} \mathrm{Hg}^{*}\right.$} \\
\hline$\geq 90$ & $5183(98.4)$ & Ref. & $<0.0001$ \\
\hline$<90$ & $84(1.6)$ & 1.41 (1.19 to 1.68$)$ & $<0.0001$ \\
\hline \multicolumn{4}{|l|}{ Respiratory rate (breaths/min)* } \\
\hline $10-29$ & $5145(97.7)$ & Ref. & 0.003 \\
\hline$<10$ and $\geq 30$ & $122(2.3)$ & $1.30(1.13$ to 1.50$)$ & 0.003 \\
\hline \multicolumn{4}{|l|}{ Glasgow Coma Scale score* } \\
\hline $13-15$ & $4182(79.4)$ & Ref. & $<0.001$ \\
\hline $9-12$ & 401 (7.6) & $1.49(1.36$ to 1.62$)$ & $<0.001$ \\
\hline $3-8$ & $684(13.0)$ & 2.01 (1.85 to 2.18 ) & $<0.001$ \\
\hline \multicolumn{4}{|l|}{ Transferred in from another centre } \\
\hline No & $2750(52.2)$ & Ref & $<0.001$ \\
\hline Yes & $2517(47.8)$ & 0.82 (0.78 to 0.86$)$ & $<0.001$ \\
\hline \multicolumn{4}{|l|}{ Mechanism of injury } \\
\hline Motor vehicle collision & $1121(22.0)$ & Ref. & $<0.001$ \\
\hline Fall from standing height & $1683(32.0)$ & 0.89 (0.80 to 1.00$)$ & $<0.001$ \\
\hline Fall from more than standing height & $1674(31.8)$ & 0.94 (0.85 to 1.05$)$ & $<0.001$ \\
\hline Penetrating injury & $56(1.1)$ & 1.55 (1.24 to 1.94$)$ & $<0.001$ \\
\hline Blunt object & $369(7.0)$ & 0.99 (0.88 to 1.13$)$ & $<0.001$ \\
\hline Other & $364(6.9)$ & 0.94 (0.83 to 1.06$)$ & $<0.001$ \\
\hline \multicolumn{4}{|l|}{ Discharge destination } \\
\hline Home & $2392(45.4)$ & Ref. & $<0.001$ \\
\hline Transfer to acute care & $815(15.5)$ & 1.35 (1.26 to 1.44$)$ & $<0.001$ \\
\hline Transfer to long-term care & $321(6.1)$ & 2.20 (2.00 to 2.42$)$ & $<0.001$ \\
\hline Rehabilitation & $1361(25.8)$ & $1.88(1.78$ to 2.00$)$ & $<0.001$ \\
\hline Other & $378(7.2)$ & $1.42(1.30$ to 1.56$)$ & $<0.001$ \\
\hline
\end{tabular}




\begin{tabular}{|c|c|c|c|}
\hline Variable & $n(\%)$ & $\begin{array}{l}\text { Geometric mean ratio of costs } \\
\qquad(95 \% \mathrm{Cl})\end{array}$ & $p$ value \\
\hline \multicolumn{4}{|l|}{ Payer agency } \\
\hline Provincial plan & $3851(73.1)$ & Ref. & 0.5 \\
\hline Automobile plan & $916(17.4)$ & 1.04 (0.94 to 1.16$)$ & 0.5 \\
\hline Workers' safety plan & $158(3.0)$ & $0.98(0.87$ to 1.11$)$ & 0.5 \\
\hline Other & $210(4.0)$ & 1.06 (0.95 to 1.19$)$ & 0.5 \\
\hline None or missing & $132(2.5)$ & 0.92 (0.79 to 1.07$)$ & 0.5 \\
\hline
\end{tabular}

to be due to duration of care (general ward) or to intensity of care (operating room, ICU, medical imaging, paraclinical services), a strong negative association between hospital resource use and mortality was observed for intensity of care. For complications, the positive association was stronger for duration of care. Including deaths in the competitive risk model did not lead to significant changes in the results.

\section{Discussion}

In this retrospective, multicentre cohort study, we observed significant interhospital variation in risk-adjusted hospital resource use for patients with TBI in an inclusive Canadian trauma system. The largest interhospital variation was observed for the operating room and the smallest for the general ward. Anatomic injury severity and discharge destination were the most important determinants of hospital resource use intensity. In addition, hospitals with higher risk-adjusted resource use had a lower riskadjusted incidence of mortality but a higher incidence of complications; intensity of care (imaging, surgery, ICU and paraclinical services) explained correlations with mortality whereas duration of care (ward) explained correlations with complications. Correlations were strongest for younger patients (aged $<65 \mathrm{yr}$ ) and level I and II centres.

Mean hospital resource use reported for TBI admissions in England and Wales was higher than in Quebec at Can\$27773 (£15 462), ${ }^{31}$ compared with Can $\$ 10108$. The inclusion of the costs of prehospital transport and differential costs for specific surgeries in the British cohort may explain these differences.

Observed variations in risk-adjusted costs across trauma centres are consistent with previous research showing substantial variations for general trauma admissions. ${ }^{32}$ Centres with higher than average resource use intensity tended to have a higher designation level (all level I centres, 2 of 5 level II centres, 3 of 21 level III centres and no level IV centres) and therefore tended to be large, highly specialized, urban trauma centres. This observation is consistent with studies suggesting that high resource use is related to resource availability. ${ }^{33-35}$ Interhospital variation was high for resource use in the operating room and moderate for all other activity centres. This result may suggest variation in neurosurgical procedures, which could be explained by the controversy surrounding the results (and the interpretation of the results) for decompressive craniectomy from high-profile randomized controlled trials. ${ }^{36,37}$ Indeed, a recent consensus statement recognized the lack of evidence of effectiveness for improving patient outcomes but recommended decompressive craniotomy in specific situations, often dictated by physician gestalt and physicianfamily shared decision-making. ${ }^{38}$

Our results on the determinants of hospital resource use are also consistent with previous studies; age, GCS score and discharge status have previously been identified as substantial drivers of costs for TBI admissions. ${ }^{31}$ The increase in costs for patients discharged to long-term care or rehabilitation facilities is probably explained by delays in access to postacute care and suggests that reducing these delays may be part of the solution to reducing acute care costs.

Observed associations between hospital resource use intensity and outcomes should be interpreted with caution but may be useful for generating hypotheses. The negative association between hospital resource use and mortality and the positive association with complications may be suggestive of a trade-off between survival and adverse events. Factors such as level of care decisions, related to goals of care and including withdrawal of life-sustaining therapies, ${ }^{39-41}$ could partially explain the negative correlation between hospital resource use and mortality. Indeed, significant interhospital variation in withdrawal of lifesustaining therapies for TBI admissions across Canadian trauma centres has previously been reported..$^{39-41}$ Results suggest that there is a need to improve prognostic tools in this population to aid physicians and families in decisionmaking. The positive correlation between hospital resource use and complications is more difficult to interpret as on the one hand, more tests and interventions and longer hospitals stays are likely to increase the risk of complications, and on the other hand, patients who develop complications require more resources. An analysis of disability and quality of life would help us to better understand whether increased hospital resource use leads to lower mortality at the detriment of acceptable functional outcome. 
A

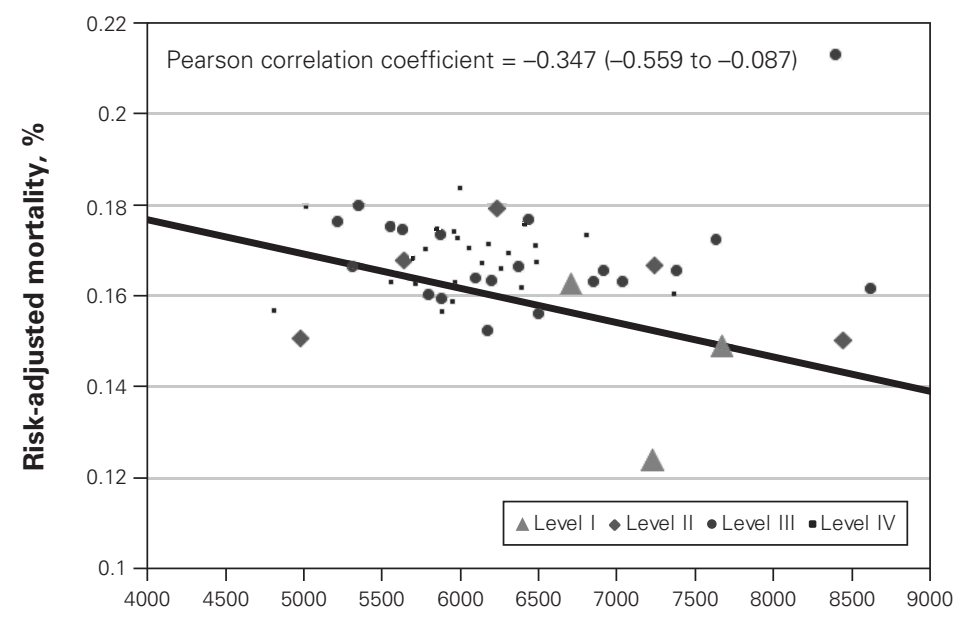

Risk-adjusted resource use, Can\$

B

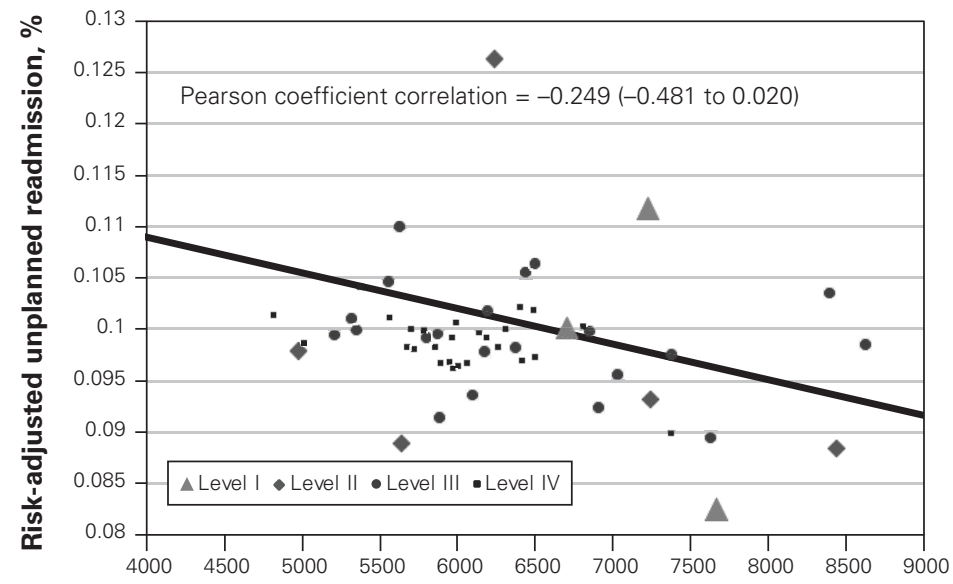

Risk-adjusted resource use, Can\$

C

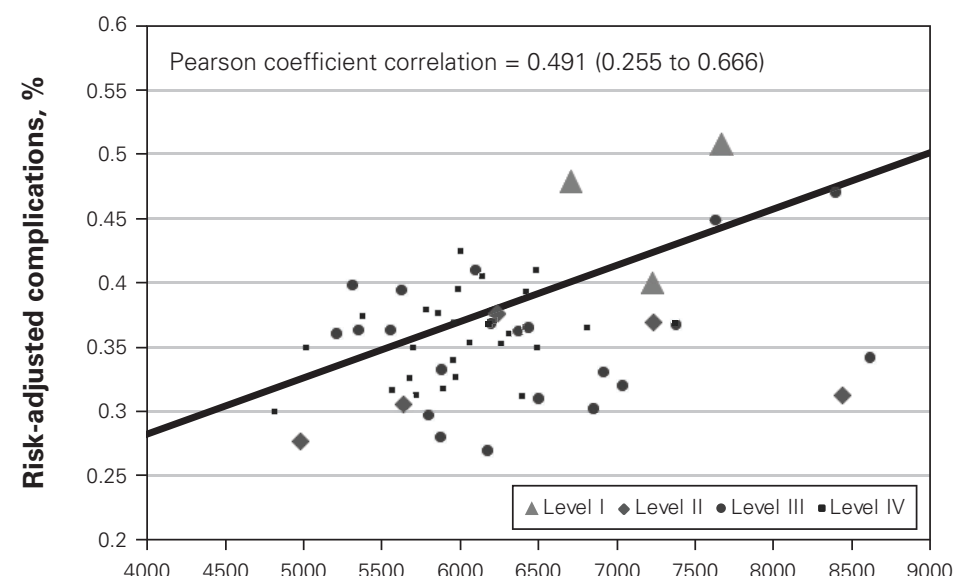

Risk-adjusted resource use, \$Can

Fig. 2. Associations between hospital resource use and (A) mortality, (B) readmission and (C) complications for patients with traumatic brain injury. Values in parentheses are $95 \%$ confidence intervals. 
Table 3. Associations between risk-adjusted hospital resource use and risk-adjusted clinical outcome in subgroup analysis

\begin{tabular}{|lccc} 
& & Pearson correlation coefficient (95\% Cl); outcome \\
Subgroup & Mortality & Complications & Readmission \\
\hline $\begin{array}{l}\text { Whole sample } \\
(n=55)\end{array}$ & -0.347 & 0.491 & -0.249 \\
\hline$<65 \mathrm{yr}$ & $(-0.559$ to -0.087$)$ & $(0.255$ to 0.666$)$ & $(-0.481$ to 0.020$)$ \\
$(n=50)$ & -0.441 & 0.528 & -0.179 \\
\hline $\begin{array}{l}265 \mathrm{yr} \\
(n=55)\end{array}$ & $(-0.638$ to -0.181$)$ & $(0.288$ to 0.700$)$ & $(-0.434$ to 0.106$)$ \\
\hline $\begin{array}{l}\text { Isolated TBI } \\
(n=53)\end{array}$ & 0.086 & 0.356 & -0.249 \\
\hline $\begin{array}{l}\text { Severe TBI (MAIS } \geq 4) \\
(n=47)\end{array}$ & $(-0.184$ to 0.343$)$ & $(0.097$ to 0.565$)$ & $(-0.480$ to 0.020$)$ \\
\hline $\begin{array}{l}\text { Level I and II trauma centres } \\
(n=8)\end{array}$ & 0.233 & 0.399 & -0.486 \\
\hline Cl $=$ confidence interval; MAIS $=$ Maximum Abbreviated Injury Scale; TBI = traumatic brain injury. & $(0.141$ to 0.602$)$ & $(-0.666$ to -0.244$)$ \\
\hline
\end{tabular}

This study has several strengths. The use of the Quebec trauma registry provides high population coverage of moderate to severe cases of TBI in the province, as $90 \%$ of major trauma cases are treated in trauma centres. ${ }^{42}$ Furthermore, rigorous data quality assurance processes including standardized procedures for data collection, unified inclusion criteria, coding forums and coding quality algorithms ensure high data quality $(98 \%$ accuracy in stratified random sample chart reabstraction [L.M. and Amina Belcaïd, Centre de recherche du Centre hospitalier universitaire de Québec, Hôpital de l'Enfant-Jésus: unpublished data, 2017]). Another strength of this study is the reproducibility of the method used to estimate hospital resource use. Activity-based costing can be applied with routinely collected data and allows comparisons of hospital resource use between trauma centres because it is not affected by temporal or geographic pricing fluctuations.

\section{Limitations}

This study has some limitations that should be considered in the interpretation of the results. First, hospital resource use estimates did not include the cost of laboratory tests, medications or blood products. Although we do not have data specific to TBI populations, laboratory tests represent $4.2 \%$ of total acute care costs in Canada, ${ }^{43}$ blood products or blood management represent $1.4 \%$ of total acute care costs for trauma admissions in the $\mathrm{US}^{44}$ and medications are estimated to represent $8.3 \%$ of total hospital costs in the US. ${ }^{45} \mathrm{We}$ therefore believe that excluding these costs probably had little impact on our results. In addition, activitybased costs do not include physician fees, which were not available for this study. This should be the subject of future research but because physicians are paid on a fee-for-service basis in Canada, ${ }^{46}$ fees are influenced by geographic and pricing fluctuations. Also, hospital resource use estimates give global approximations. For example, we did not have cost information specific to types of surgery, number of scans or duration of paraclinical services. We instead used a fixed (average) cost for each. This approximation probably also led to an underestimation of the true costs but has the advantage of being reproducible with routinely collected registry data. Second, interhospital comparisons may be subject to residual confounding because of missing confounding variables (e.g., pupillary reactivity, episodes of intracranial hypertension) or included adjustment variables subject to measurement error. For example, physiologic reaction to injury is based on a single evaluation of physiologic parameters (GCS score, SBP, respiratory rate) taken on arrival in the emergency department. Indeed, lack of available data on documented risk factors for TBI prognosis such as unilateral or bilateral fixed pupils, TBI prognostic scores (e.g., Marshall score) and changes in GCS may have led to an overestimation of interhospital variability. In addition, imputation of these parameters is based on the assumption that data are missing at random, which is impossible to verify formally. However, consultation with experts on the reason for missing data and previous simulation studies on the Quebec trauma registry suggest that hospital comparisons adjusted using imputed data are valid provided the imputation model is correctly specified. ${ }^{47,48}$ The AIS injury severity score is subject to problems of inter- and intrarater reliability and represents a consensusderived score largely based on mortality risk. ${ }^{49,50}$ Also, since we used administrative data, comorbidities are likely to have been underreported. ${ }^{51}$ Finally, the exclusion of deaths may have led to a survival bias. However, sensitivity analyses based on competitive risk models did not lead to different conclusions.

\section{Conclusion}

This study highlights important interhospital variation in hospital resource use for adults with TBI. We also pinpointed high resource use for patients transferred to rehabilitation units and long-term care centres, probably 
because of discharge delays. In addition, even though associations should be interpreted with caution, we observed that hospitals with higher risk-adjusted hospital resource use intensity tended to have lower mortality but a higher incidence of complications. Future research should strive to verify hypotheses generated by these results to identify ways to improve injury care quality and efficiency. In future steps, we will look to advance knowledge on hospital and physician characteristics that may explain interhospital variation in hospital resource use intensity and explore the role of low-value clinical practices. We also need to obtain a better understanding of the association between hospital resource use and long-term, patient-oriented outcomes such as disability and quality of life.

Acknowledgements: The authors thank Amina Belcaïd for her expertise regarding data sources and Xavier Neveu for his expertise concerning statistical analyses.

Affiliations: Département de médecine sociale et préventive (Assy, Moore, Porgo, Farhat, Tardif, Turgeon) and axe Santé des populations et pratiques optimales en santé (Population Health and Optimal Health Practices Research Unit) (Assy, Moore, Porgo, Farhat, Tardif, Lauzier, Turgeon), Traumatologie - Urgence - Soins intensifs (Trauma - Emergency - Critical Care Medicine), Centre de recherche du Centre hospitalier universtaire de Québec, Hôpital de l'Enfant-Jésus, Université Laval, Québec, Que.; Institut national d'excellence en santé et en services sociaux (Truchon, Clément), Québec, Que.; Departments of Critical Care Medicine, Medicine and Community Health Sciences (Stelfox), O'Brien Institute for Public Health, University of Calgary, Calgary, Alta.; School of Public Health and Preventive Medicine (Gabbe), Monash University, Melbourne, Australia; Department of Medicine (Lauzier) and Division of Critical Care Medicine (Lauzier, Turgeon), Department of Anesthesiology and Critical Care Medicine, and Department of Surgery (Clément), Université Laval, Québec, Que.

Competing interests: None declared.

Funding: This study was funded by Fonds de recherche du Québec Santé (FRQS) (grant no. 112775) and the Canadian Institutes of Health Research (CIHR) (grant no. 358052). L. Moore and F. Lauzier are recipients of FRQS salary support awards. H. Stelfox is supported by a CIHR Embedded Clinician Researcher award. A. Turgeon holds the Canada Research Chair in Critical Care Neurology and Trauma.

Contributors: C. Assy, L. Moore, T. Porgo and B. Gabbe conceived the study. C. Assy and L. Moore acquired the data, which all authors analyzed. C. Assy, L. Moore and T. Porgo wrote the article, which all authors critically revised. All authors agreed to be accountable for all aspects of the work.

Content licence: This is an Open Access article distributed in accordance with the terms of the Creative Commons Attribution (CC BYNC-ND 4.0) licence, which permits use, distribution and reproduction in any medium, provided that the original publication is properly cited, the use is noncommercial (i.e., research or educational use), and no modifications or adaptations are made. See: https://creativecommons. org/licenses/by-nc-nd/4.0/

\section{References}

1. Get the facts about TBI. Atlanta: Centers for Disease Control and Prevention. Available: www.cdc.gov/traumaticbraininjury/get_the_ facts.html(accessed 2020 Sept. 15).

2. Head injuries in Canada: a decade of change (1994-1995 to 2003-2004). Ottawa: Canadian Institute for Health Information; 2006.
3. Neurological disorders: public health challenges. Geneva: World Health Organization; 2006.

4. Traumatic brain injury and concussion: severe TBI. Atlanta: Centers for Disease Control and Prevention. Available: www.cdc.gov/ traumaticbraininjury/severe.html (accessed 2018 Oct. 16).

5. Moore L, Evans D, Hameed SM, et al. Mortality in Canadian trauma systems: a multicenter cohort study. Ann Surg 2017;265: 212-7.

6. McKinney M. Traumatic differences. Study finds variations in costs but not outcomes. Mod Healthc 2012;42:17.

7. Mitchell RJ, Curtis K, Braithwaite J. Health outcomes and costs for injured young people hospitalised with and without chronic health conditions. Injury 2017;48:1776-83.

8. Miller CM, Shi J, Wheeler KK, et al. Chronic conditions and outcomes of pediatric trauma patients. 7 Trauma Acute Care Surg 2013;75:250-7.

9. De Coster C, Bruce S, Kozyrskyi A. Use of acute care hospitals by long-stay patients: Who, how much, and why? Can 7 Aging 2005;24(Suppl 1):97-106.

10. Sources de données et métadonnées: AS-471. Québec (QC): Ministère de la santé et des services sociaux; updated 2016 Jul. 26. Available: www.msss.gouv.qc.ca/professionnels/documentation -sources-de-donnees-et-indicateurs/sources-de-donnees-et-metadonnees/ as-471/ (accessed 2020 Sept. 15).

11. Rapport financiers annuels des établissements 2015-2016. Québec (QC): Ministère de la santé et des services sociaux; 2016. Available: http://publications.msss.gouv.qc.ca/msss/document-001671/ (accessed 2020 Sept. 15).

12. Bilan de qualité et de performance en traumatologie: guide d'accompagnement pour l'analyse des statistiques descriptives et des indicateurs de processus et de résultats. Québec (QC): Institut national d'excellence en santé et en services sociaux; 2017.

13. Schünemann H, Brożek J, Guyatt G, et al., editors. GRADE handbook for grading quality of evidence and strength of recommendations. GRADE Working Group; updated Oct. 2013. Available: guidelinedevelopment.org/handbook (accessed 2020 Sept. 15).

14. Guidelines for the economic evaluation of health technologies: Canada. 4th ed. Ottawa: Canadian Agency for Drugs and Technologies in Health; 2006, updated 2017 Mar. 28.

15. Porgo TV, Moore L, Truchon C, et al. Patient-level resource use for injury admissions in Canada: a multicentre retrospective cohort study. Injury 2019;50:1192-201.

16. Omar M, Moore L, Lauzier F, et al. Complications following hospital admission for traumatic brain injury: a multicenter cohort study. 7 Crit Care 2017;41:1-8.

17. Moore L, Stelfox HT, Turgeon AF, et al. Rates, patterns, and determinants of unplanned readmission after traumatic injury: a multicenter cohort study. Ann Surg 2014;259:374-80.

18. Luke DA. Multilevel modeling. 1st ed. Thousand Oaks (CA): Sage Publications; 2004 Jul. 8.

19. Rysavy MA, Li L, Bell EF, et al.; Eunice Kennedy Shriver National Institute of Child Health and Human Development Neonatal Research Network. Between-hospital variation in treatment and outcomes in extremely preterm infants. N Engl f Med 2015;372:1801-11.

20. Krogstad U, Hofoss D, Veenstra M, et al. Hospital quality improvement in context: a multilevel analysis of staff job evaluations. Qual Saf Health Care 2005;14:438-42.

21. Palm R. Utilisation du bootstrap pour les problèmes statistiques liés à l'estimation des paramètres. Biotechnol Agron Soc Environ 2002;6:143-53.

22. Chernick MR, González-Manteiga W, Crujeiras RM, et al. Bootstrap methods. In: Lovric M, editor. International encyclopedia of statistical science. Berlin, Heidelberg (Germany): Springer; 2014:169-74.

23. Moore L, Stelfox HT, Evans D, et al. Hospital and intensive care unit length of stay for injury admissions: a pan-Canadian cohort study. Ann Surg 2018;267:177-82. 
24. MacKenzie TA, Grunkemeier GL, Grunwald GK, et al. A primer on using shrinkage to compare in-hospital mortality between centers. Ann Thorac Surg 2015;99:757-61.

25. Daly LE, Bourke GJ. Interpretation and uses of medical statistics. 5th ed. New York (NY): Wiley-Blackwell; 2000.

26. Moore L, Lavoie A, Turgeon AF, et al. The trauma risk adjustment model: a new model for evaluating trauma care. Ann Surg 2009;249:1040-6.

27. Schafer JL. Multiple imputation: a primer. Stat Methods Med Res 1999;8:3-15.

28. Sterne JAC, White IR, Carlin JB, et al. Multiple imputation for missing data in epidemiological and clinical research: potential and pitfalls. BM7 2009;338:b2393.

29. Flottemesch TJ, Raetzman S, Heslin KC, et al. Age-related disparities in trauma center access for severe head injuries following the release of the updated field triage guidelines. Acad Emerg Med 2017;24:447-57.

30. Austin PC, Lee DS, Fine JP. Introduction to the analysis of survival data in the presence of competing risks. Circulation 2016;133:601-9.

31. Morris S, Ridley S, Lecky FE, et al. Determinants of hospital costs associated with traumatic brain injury in England and Wales. Anaesthesia 2008;63:499-508.

32. Mabry CD, Kalkwarf KJ, Betzold RD, et al. Determining the hospital trauma financial impact in a statewide trauma system. $7 \mathrm{Am}$ Coll Surg 2015;220:446-58.

33. Jha AK, Orav EJ, Dobson A, et al. Measuring efficiency: the association of hospital costs and quality of care. Health Aff (Millwood) 2009;28:897-906.

34. Fisher ES, Wennberg DE, Stukel TA, et al. The implications of regional variations in medicare spending. Part 1: The content, quality, and accessibility of care. Ann Intern Med 2003;138:273-87.

35. Wennberg JE, Fisher ES, Goodman DC, et al. Tracking the care of patients with severe chronic illness: the Dartmouth atlas of health care 2008. Lebanon (NH): Dartmouth Institute for Health Policy and Clinical Practice; 2008.

36. Hutchinson PJ, Kolias AG, Timofeev IS, et al.; RESCUEicp Trial Collaborators. Trial of decompressive craniectomy for traumatic intracranial hypertension. N Engl 7 Med 2016;375:1119-30.

37. Cooper DJ, Rosenfeld JV, Murray L, et al.; DECRA Trial Investigators and the Australian and New Zealand Intensive Care Society Clinical Trials Group. Patient outcomes at twelve months after early decompressive craniectomy for diffuse traumatic brain injury in the randomized DECRA clinical trial. 7 Neurotrauma 2020;37:810-6.
38. Hutchinson PJ, Kolias AG, Tajsic T, et al. Consensus statement from the International Consensus Meeting on the Role of Decompressive Craniectomy in the Management of Traumatic Brain Injury: consensus statement. Acta Neurochir (Wien) 2019;161:1261-74.

39. Turgeon AF, Lauzier F, Zarychanski R, et al.; TBI-Prognosis Study Team and the Canadian Critical Care Trials Group. Prognostication in critically ill patients with severe traumatic brain injury: the TBI-Prognosis multicentre feasibility study. BMF Open 2017;7:e013779.

40. Turgeon AF, Lauzier F, Simard J-F, et al.; Canadian Critical Care Trials Group. Mortality associated with withdrawal of lifesustaining therapy for patients with severe traumatic brain injury: a Canadian multicentre cohort study. CMA7 2011;183:1581-8.

41. Thompson HJ, Rivara FP, Jurkovich GJ, et al. Evaluation of the effect of intensity of care on mortality after traumatic brain injury. Crit Care Med 2008;36:282-90.

42. Kuimi BLB, Moore L, Cissé B, et al. Access to a Canadian provincial integrated trauma system: a population-based cohort study. Injury 2015;46:595-601.

43. The cost of acute care hospital stays by medical condition in Canada: 2004-2005. Ottawa: Canadian Institute for Health Information; 2008.

44. Zbrozek A, Magee G. Cost of bleeding in trauma and complex cardiac surgery. Clin Ther 2015;37:1966-74.

45. Taheri PA, Butz DA, Greenfield LJ. Length of stay has minimal impact on the cost of hospital admission. 7 Am Coll Surg 2000;191:123-30.

46. Ridic G, Gleason S, Ridic O. Comparisons of health care systems in the United States, Germany and Canada. Mater Sociomed 2012;24:112-20.

47. Moore L, Hanley JA, Lavoie A, et al. Evaluating the validity of multiple imputation for missing physiological data in the national trauma data bank. 7 Emerg Trauma Shock 2009;2:73-9.

48. Moore L, Lavoie A, LeSage N, et al. Multiple imputation of the Glasgow Coma Score. 7 Trauma 2005;59:698-704.

49. Rating the severity of tissue damage. I. The abbreviated scale. FAMA 1971;215:277-80.

50. Rating the severity of tissue damage. II. The comprehensive scale. FAMA 1972;220:717-20.

51. Chong WF, Ding YY, Heng BH. A comparison of comorbidities obtained from hospital administrative data and medical charts in older patients with pneumonia. BMC Health Serv Res 2011;11:105. 